\title{
Design and simulation of AC-DC constant current source with high power factor
}

\author{
Hong-Li Cheng ${ }^{\dagger}$, Kuo-Jun Fan and Jian-Nan Wang \\ College of communication and information engineering \\ $X i^{\prime}$ an University of Science and Technology \\ Xi'an, 710054, China \\ E-mail: chhl@xust.edu.cn \\ 414081123@qq.com
}

\begin{abstract}
The design of high reliability, high efficiency, high power factor and low cost is the development trend of the current switching power supply. Traditional switching power supply, input current of rectifier filter circuit, which contains a large number of harmonics, will cause the power utilization efficiency decreased, low power factor and so on. In this paper, flyback topology with capacitor-less is used. The flyback switching converter controlled by ARM is designed for power factor correction, and its working principle is analyzed in detail. It can reduce the impact of high input ripple voltage caused by capacitor-less on the output voltage ripple and achieve constant current source, and to obtain high power factor by using program algorithm. Matlab/Simulink is used to verify the design, and the simulation results show that the scheme is feasible.
\end{abstract}

Keywords: Power factor correction; Flyback converter; Constant current source.

\section{Introduction}

In the field of traditional switching power supply, after the rectifier bridge is the electrolytic capacitor. These nonlinear elements make the AC input current waveform distorted, and produce harmonic interference, and reduce input power factor [1-2]. In order to improve power factor, reduce the current harmonic, there are two main methods at present: (1) Passive power factor correction [3]; (2) Active power factor correction [4-6]. This paper describes the design of a flyback AC/DC constant current source without input electrolytic capacitor, which generates the drive pulse control switch by ARM to reduce the output current ripple, to increase the input power factor, and to achieve the purpose of constant current output.

\section{System composition and Working principle}

High power factor AC-DC constant current source system composition diagram is shown in Figure 1. The system is composed of EMI circuit, auxiliary power 
circuit, flyback converter circuit, output rectifier filter circuit, output voltage sampling circuit, input voltage sampling circuit, ARM control circuit, and transformer isolation drive circuit.

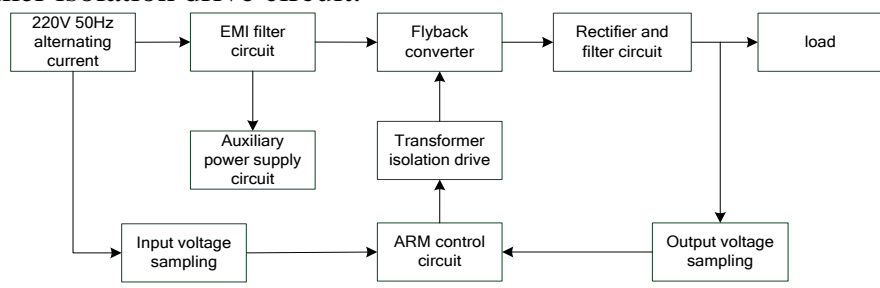

Fig. 1 system composition block diagram

$220 \mathrm{~V}, 50 \mathrm{~Hz}, \mathrm{AC}$ input through EMI filter circuit, which filter out interference signal. After rectification, the alternating current is changed into DC impulse voltage, One circuit enters into the flyback converter circuit and reduces voltage to supply the load, another circuit enters into the auxiliary power supply circuit to produce two auxiliary voltage. Two auxiliary voltages are supplied to system chip and control chip. ARM sampling the input voltage and the input current, and through program can produce PWM wave with adjustable duty ratio, which get through the isolation driving circuit to control flyback converter switch turn-on and turn-off, to achieve power factor correction and constant current output.

\section{System design}

\subsection{Control strategy}

When the flyback converter has no input filter capacitor, schematic diagram is shown in figure 2:

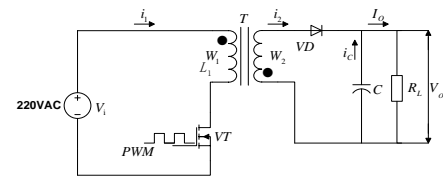

Figure. 2. The schematic diagram of flyback converter.

Flyback converter is working in the DCM mode, the input voltage is high pulse voltage, during the switch conduction period, high pulse input voltage acting on the inductor, has the following relationship, as in Eq. (1).

$$
L_{1} \frac{d T}{d t}=U_{m} \sin \omega_{o}
$$


$\mathrm{L}_{1}$ is the primary side of the transformer inductance, $\mathrm{i}_{\mathrm{L} 1}$ is transformer primary side current, $\mathrm{U}_{\mathrm{m}}$ is the peak value of input voltage, $\omega_{0}$ is power angle frequency, when the chopping frequency is much higher than the power frequency, during the switch tube conduction time, the input AC voltage can be considered unchanged. Integrating the two sides of the Eq. (1), we can get a formula about peak current $\mathrm{I}_{\mathrm{ip}}$, as in Eq. (2).

$$
I_{\mathrm{i} P}=\frac{\mathrm{d} T}{L_{1}} U_{m} \sin \omega_{o} t
$$

$\mathrm{d}$ is the switch duty cycle, $\mathrm{d}=\mathrm{ton} / \mathrm{T}, \mathrm{T}$ is the chopping cycle, flyback converter is working in DCM mode, at the end of the switch tube conduction time, energy storage in the $\mathrm{L}_{1}$ is $\mathrm{W}_{\mathrm{i}}$, as in Eq. (3).

$$
W_{\mathrm{i}}=\frac{1}{2} L_{i} I_{\mathrm{i} P}{ }^{2}
$$

The average input power from the above formula is $P_{i}$ as in Eq. (4).

$$
P_{\mathrm{i}}=\frac{\mathrm{d}^{2} T}{2 L_{1}} U_{m}^{2} \sin ^{2} \omega_{o} t
$$

Output power is $\mathrm{P}_{\mathrm{o}}$, as in Eq. (5).

$$
P_{\mathrm{o}}=U_{O} I_{O}
$$

By the total power conservation, $P_{i} \eta=P_{o}$, simultaneous equation (4) and (5), $\mathrm{d}$ can be get, as in Eq. (6).

$$
\mathrm{d}=\frac{1}{U_{m} \sin \omega_{o} t} \sqrt{\frac{U_{o} I_{o} * 2 L_{1} * \mathrm{f}}{\eta}}
$$

$\mathrm{U}_{\mathrm{o}}$ and $\mathrm{I}_{\mathrm{o}}$ are the set value, $\mathrm{L}_{1}$ and $\mathrm{f}$ are hardware parameters, which can be considered constant value, $\mathrm{d}$ and $\mathrm{U}_{\mathrm{m}} \sin \omega_{\mathrm{o}}$ t are inversely proportional, according to the duty cycle and the input sinusoidal voltage, the duty cycle is the smallest when the input voltage is maximum, the duty cycle is the maximum when the input voltage is smallest. According to the input voltage and duty relationship, write control program, after sampling input voltage and output voltage into ARM, through the procedure produces variable duty cycle pulse to control the main circuit switch of flyback converter in DCM mode, the output voltage ripple of the flyback converter without input filter capacitor is controlled to achieve the purpose of the constant current output. 


\subsection{Program Design}

The system program flow chart is shown in Figure 3, ARM is used as the main control chip. After system power on, the initial duty cycle $\mathrm{D}_{0}$ is given, then output voltage and input voltage are sampled, then read it, and judge whether open circuit, if the system is open circuit ,output duty ratio D is 0 ,and turn off the flyback converter main switch, if not, the program continue to run. By calculating, get the corresponding duty ratio of PWM wave with different width, by isolating drive circuit control the flyback converter switch, then continue to read the $\mathrm{AD}$ conversion results, followed by reciprocating, the normal running of the program.

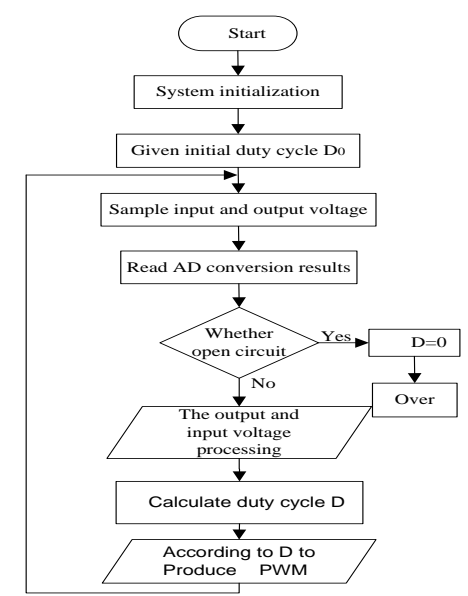

Fig. 3 System program flow chart.

\subsection{Hardware parameter design}

Single-stage flyback converter's input voltage range is $175 \mathrm{~V}-265 \mathrm{~V}$, frequency is $50 \mathrm{~Hz}$, output voltage is $28 \mathrm{~V}-38 \mathrm{~V}$ and output current is $2.1 \mathrm{~A}$. The choice of reflection voltage $\mathrm{V}_{\text {or }}$ is $270 \mathrm{~V}$, . $\mathrm{D}=0.5$, the ferrite core $\mathrm{EC}-35$ can be used to design the flyback converter transformer, because the output power of the constant current source is $59 \mathrm{~W}-80 \mathrm{~W}$. As $\mathrm{Eq}(7)$.

$$
I_{p}=\frac{2 P_{\mathrm{o}}}{V_{\text {in } \min } D_{\text {max }} \eta}
$$

The $V_{\text {inmin }}=175 \mathrm{~V}$ in the formula, so $I_{p}=2.18 \mathrm{~A}$. It is generalized from inductance calculation formula, as $\mathrm{Eq}(8)$. 


$$
L_{p}=\frac{2 P_{\mathrm{o}} T}{I_{p}^{2}}
$$

$\mathrm{T}$ is switching tube period. Bringing current and maximum output power of 8th calculating formula into 9th calculating formula, we will get $\mathrm{Lp}=765 \mathrm{uF}$. The number of turns is calculated as $\mathrm{Eq}(9)$.

$$
N_{p}=\frac{L_{\mathrm{P}} I_{\mathrm{p}} * 10^{-8}}{A_{p} \Delta B}
$$

Ap is the cross section area of the transformer core, The Ap of EC35 core is $112 \mathrm{~mm} 2, \Delta \mathrm{B}$ is calculated by the general $0.25 \mathrm{~T}$, from 10 th formula, the primary side is 63 turns. According to the calculation of reflected voltage, turns ratio is 7 , so the vice side is 9 turns.

\section{Simulation and verification}

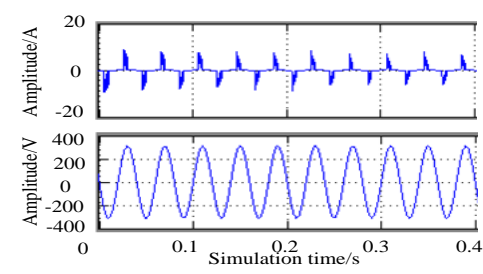

(a)

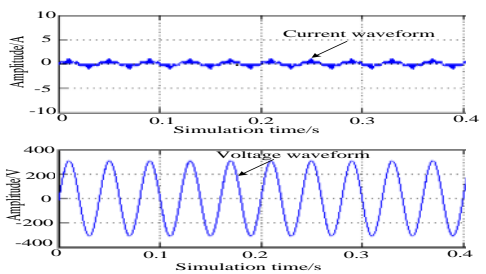

(b)

Fig.4. Waveform of input voltage and the input current with capacitor and capacitor-less.

Based on the above parameters, the circuit with capacitor is carried out by Simulink. When input sinusoidal voltage gets through the rectifier filter circuit, the waveform of input voltage and input current are shown in Figure 4(a). Current waveform presents spike pulse shape, due to the lower power factor. This kind of current contains a large number of high harmonics, when flowing through the power grid, it will cause serious harmonic pollution, the voltage waveform distortion, even can cause the electric equipment heating damage.

After removing the input filter capacitor, in accordance with the new control method, the simulation waveforms are shown in Figure 4(b), the phase of the input current is similar to the input voltage, the power factor close to 1 . The waveform of the output current is shown in Figure 5, the ripple is only $56 \mathrm{~mA}$. The designed output current target is $2.1 \mathrm{~A}$, and the stability of the constant current is $1 \%$. Stability is higher than the market products, the result achieved the constant current effect, and simulation results verify the feasibility and 
integrity of the design ideas.

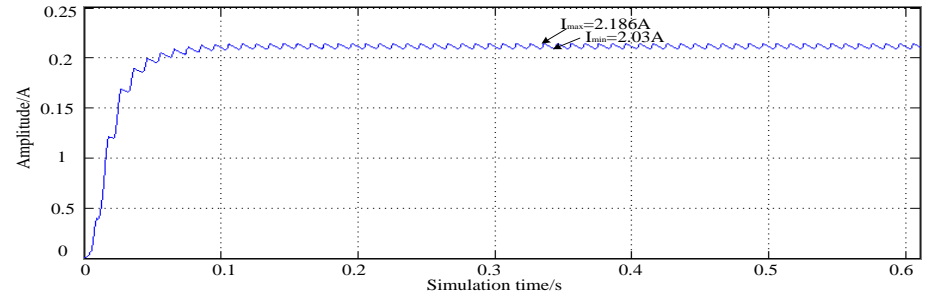

Fig.5. Waveform of the output current

\section{Conclusion}

This paper introduces the flyback converter with capacitor-less, It works in DCM mode to realize power factor correction, then using ARM programming to reduce the impact of input high pulse voltage on the output voltage ripple and achieve a stable output voltage. Finally, according to the hardware design parameters of the system and using Matlab/simulink to complete the simulation design. From the simulation results, it can be seen that the input voltage phase is the same to the output current and the power factor is close to 1 , and the stability of current source's output current is high, to achieve the goal of power factor correction and output constant current.

\section{Reference}

1. Shen-Qiang Huang. A research on LED drive power without electrolytic capacitors based on flyback converter [D], Guangxi University, 2004.

2. Xia Shen, Hong-Cheng Wang, Lin Jiang, Jin Xu, Wei Fang. Design of LED lighting power supply with high power factor [J]. Electric Machines and Control, 2011, 06:140-143.

3. Jian-Jun, Fang-hua Zhang, Yi-Jie Yu. High power factor AC-DC LED drivers without electrolytic capacitors [J]. Transactions of China electrotechnical society, 2012, 12: 79-86+93.

4. Yang Yang, Xin-Bo Ruan, Zhi-Hong Ye. A feed-forward scheme to reduce output current ripple of an electrolytic capacitor-less AC/DC LED driver [J]. Proceedings of the CSEE, 2013, 21:18-25+189.

5. H. P. Yee, Ph. D. An EMI Suppression on MOSFET Driver. Applied Power Electronics Conference and Exposition [J]. IEEE APEC'97, Conference Proceedings 1997:242-248.

6. P. K. Dash, N. Nayak. Nonlinear control of voltage source converters in AC-DC power system [J]. ISA Transactions, Vol.53, 2014:1268-1285. 